\title{
Digital Literacy and New Technological Perspectives
}

\author{
Elvia Ilaria Feola
}

Department of Philosophical Social Sciences of Education and Training, University of Salerno, Italy

Copyright $(\mathcal{C} 2016$ by authors, all rights reserved. Authors agree that this article remains permanently open access under the terms of the Creative Commons Attribution License 4.0 International License.

\begin{abstract}
This paper aims to reflect on the implications and challenges that experts in the field have to deal with when you want to evaluate the performance in the use of digital technologies in teaching. The argument stems from a contextual and social assessment, and then proceeds to an application and methodological connotation of digital literacy activities. The work is driven by a heuristic and multidisciplinary view of the topic, highlighting not only the technical and computer skills of the learner, but especially critical thinking, problem solving, collaboration, research; bringing out a three-dimensional vision technology; cognitive/metacognitive; ethical/social, then, a complex combination of skills, abilities and knowledge. It was created an experiment in the university context, with the goal of creating a digital learning environment in which new technologies are used in order to create new content, new ways of teaching and learning, approaching the teaching experience to that of life daily and vice versa. He conducted a study/quantity in order to check whether the student, working on the use of new technologies, emerge some of its dimensions of digital literacy, and in what mode of action and reflection, surfacing that size.
\end{abstract}

Keywords Digital Literacy, Media Education, Search

\section{Introduction}

Today's society demands more and more numerous and varied skills, which must be used not only in order to strengthen individual capacity to use the information for personal empowerment and social, but also to address the potential risks associated with the mass media and the digital media. In this perspective comes the digital and media literacy to make responsible choices and access tracking information and sharing materials and understanding information and ideas; analyze messages in a variety of formats by identifying the author, purpose, point of view and assessing the quality and credibility of the content; creating content in a variety of formats for authentic purposes, making use of language, images, sounds, and new digital and technological tools; reflect on their own behavior and their communicative behaviors by considering social responsibility and ethical principles; and, finally, to undertake social action working individually or collaboratively to share knowledge and solve problems in the family, at work, in the community, and participating as a member of the community.

In recent decades, the role played by formal education agencies was not only questioned, supplanted, at least in part, by educational agencies non - formal and informal. This is because they are activated and requests forms of learning very different. The learning that is generated by the use of the media, as opposed to the traditional one, makes use of multiple intelligences and multisensory [1], able to engage and motivate the subject. In addition, the supremacy of the rational dimension of learning, based on logical reasoning, has been questioned in favor of the affective dimension/creative/body. The media carry out an epistemological and methodological pluralism capable of redefining education, resulting in new cultural forms, teaching approaches no longer focused on a vertical relationship (one-many), but horizontal and based on the connectionist paradigm and a new vision of the world.

It called into question the very concept of education, since they are not only more requests the classic skills of reading, writing and functional abilities, but other forms of literacy (audiovisual, television, digital, cine-literacy, etc.). The new form of literacy challenge the former based on a written culture and setting text-based teaching, redefining new structured communication codes according to the various social, economic and historical contexts in which they are produced, distributed and used. In addition, it aspires to develop critical understanding and active participation of the subjects. It follows that the change will have to be focused on the critical analysis and creative production. However, the crux remains the intellectual capacity to select and process the information, and therefore, technologies should be seen as "philosophical devices" capable of shaping the living environment of the individual, transforming the space-time organization of life, affect social action and cultural universes and the ways in which individuals relate to reality, to others and to themselves.

New technologies blazing new editing capabilities of communication processes in order to make them much more 
differentiated and complex, but the same time, more effective and motivating. Specifically, the new media offer endless possibilities for action on the content, as it allows us to change, transform, process, compare and interpret in a personal way the contents themselves. In addition, they present themselves as instruments capable of implementing the receiving, processing and mediation of learning content. It is therefore necessary that young people exploit this potential offered by technology and become active builders and protagonists of the future social, cultural, economic and political society. However, to achieve these skills is essential to back up the subject through the solicitation of new ways of thinking and interpreting the world. You must therefore create creative learning spaces and plan exciting activities and multiple; create a teaching related to the problems of daily life, which generate adequate tools to teach reading and media to design and implement media education paths.

Because until now exposed reinforces the need for future teachers to possess the basic skills in order to contribute to the achievement of broader digital competence.

This research work aims to develop a training methodology aimed at developing digital skills in future teachers.

\section{Theoretical Framework}

Despite the concept and purpose of digital literacy they are in vogue for over thirty years, only in recent years have become fully operational in the educational reflection. However, the integration of new media and technology in education is still poor, despite the mass media help to spread the concept and the importance of digital literacy. The goal is to realize what has been prepared by art. 37 of the Directive of the European audiovisual media services , which not only takes into account the active role of organizations such as UNESCO and the European Commission (EC) for the development of media literacy, but it has the recognition and identifies media education in political agenda [2].

The focus should be placed on the personal and social structures devoted to the construction and organization of knowledge. Educational research, therefore, aims to provide realistic working hypotheses and models congruent with the goals posed by educational institutions [3]; this in order to generate a more informed reflection on why and how to use digital media in education.

The first author to propose a definition of digital literacy is Gilster [4], which emphasizes that it is crucial to acquire especially the capacity for critical thinking and evaluation of information, rather than technical skills. In this vision it binds to Erstad [5] which proposes a definition of digital literacy as a set of skills, knowledge and attitudes in the use of media to handle the challenges of the learning society. This definition takes a broad view of its own because it binds to the challenges of what is called the learning society, meaning a look on the most active companies, process-oriented, different then by words such as the network society, the knowledge and information [6].

Digital literacy can be defined as the ability to use technological applications and the ability to make use of these technologies for personal and collective occurrences. However, above all this latter aspect it has given rise to very important issues concerning the dissemination of new technologies among populations. Many people, in fact, can not avail itself of the technology as it does not own them, and this precludes them from actively participate in the knowledge society and to its development.

Internationally also we need a responsible use of technology has prompted the European Commission to issue in December 2006 a Recommendation on key competences for lifelong learning and require a paradigm shift compared to the traditional education system [7]. The goal is to ensure everyone full citizenship in the information society, developing young people's ability to learn to learn, critical to be autonomous, develop and/or potential for their skills and design interventions in their life context and work. This objective, however, is accessible only if you become more familiar with new technologies and commit critically, so as to allow the subject to retrieve, assess, store, produce, communicate, participate, present and exchange information through collaborative networks.

Effective performance and a socially recognized action is determined by the internal resources (knowledge, understanding, skills, operational schemes, motivations, values and interests, etc.) and external (technologies, organization of work, institutions) of the subject.

The European Union, in a research report defines media literacy as the skills and expertise needed to promote development, self- aware and in the new communicative environment - digital, global and media - information society. This definition, in addition to the advantage of maintaining a firm distinction between the result (literacy) and the process (education), also allows you to encompass the steps that have taken place on the evolutionary plane than the issue of the specific skills, specific to each class of languages. This suggests that the subject is not called only to acquire new knowledge, but to learn to learn. Such a process can only be if teachers and educators prepare, orient, they differentiate and organize, knowingly and flexibly, the teaching/learning activities required by the media world and are capable of designing media education paths.

For the author Buckingham [8] media education is a teaching-learning process aimed not only literacy of media languages but also and above all, to support the development of important critical skills for an active use of the media. The ability to produce and reuse forms of communication and media tools in a creative way, becomes the most important strategy in order to promote digital skills of young people. The media education promotes educational-teaching methodology is based on the use of cognitive processes of both metacognitive processes employed by the media and global communication and is configured as a new horizon epistemological and methodological able to focus the main 
dynamics of construction of social meaning, therefore not acting as a defensive strategy, but as a project aimed at the development of a conscious and productive communication consumption [9].

Rivoltella [10] notes that the "old" teaching practices, built on the read and write just textual footsteps, must change to new prospects capable of changing the different languages in "cognitive keyboards", available and accessible to all learners.

\section{Research}

The research emphasizes the critical understanding of the media, while the other has strengthened the focus on the productive/creative dimension, it prompted precisely by the development of digital media. The first action taken to carry out the research was to design and develop a training methodology aimed to develop in people, technology skills, cognitive and ethical. Later he tried to consolidate the training methodology helped by the participation of university students. The recipients, in fact, were 162 students attending the course of Laboratory of General Education and Educational Technology of the degree course in Primary Education Sciences of the University of Salerno. The course was delivered in e-learning, making use of the open source platform.

The employed research plan was to "almost experimental one-group", which involves the use of the same group both as a control group, both as experimental group.

The aim of the research is to increase significantly in the experimental group digital skills. Specifically it aims to improve the ability to select relevant information for solving a problem; the ability to "surf" the knowledge; the ability to read and understand the texts; the ethical competence in being able to take responsibility for the consequences in the activity medial.

The assessment tools used were of four types: the Instant DCA [11] (Digital Competence Assessment) for the detection of digital research participant skills; R-I-Z-A model [12] to evaluate the acquisition of digital skills; assessment rubrics and self-evaluation of activities declined from any profile of competence and checks administered during the course.

The Instant DCA is a questionnaire easy to apply and verify that analyzes the three dimensions: technological, cognitive and ethical. The items related to the technological dimension mainly to the "ability to identify and solve" the difficulties that arise working with the media and the ability to read and interpret typical interfaces. The cognitive dimension measures the ability to understand the texts and data organization, analysis and critical evaluation of the relevance and reliability of information. The ethical dimension relates to cross-cutting aspects such as the protection of personal data, respect of netiquette and awareness of the social implications of the use of technologies.
For the application of the model R-I-Z-A they were built of outgoing competence profiles, following the directions stated in Trinchero [13].

The R-I-Z-A model is structured in accordance with: (R) resources: understood as the knowledge and basic skills of the student; (I) interpretation: as the student defines situations; $(Z)$ action: as the student acts in response to a problem; (A) self-regulation: as the student based on the experiences change their strategies according to the stresses from the environment.

According to Trinchero [14] the four components of competence emerge only when the subject is facing problems. At the end of a precise recognition of the acquisition of digital skills by learners, it was taken into account: the structures of interpretation, have been identified of competence descriptors actually observable; of action structures, operations that students should have put in place to tackle the task have been described; of the self-structures, they have been formulated the effectively detectable competence descriptors.

With regard to the descriptors of the output of each digital competence profiles they were declined in the following three levels: sufficient, good, very good and three evaluation categories were built.

It was chosen to use the address book for the evaluation and self-assessment of activities in that it allows, rather than assigning a single score, a measure of student performance using criteria ranging from a minimum to a maximum. Indeed, the book allows you to achieve an objective evaluation score of the learning process and, simultaneously, allows to combine the uniqueness of the references and the variety of possible routes that students can take [15].

As the scientists say Castoldi and Martini [16] define clearly and explicitly the evaluation criteria is essential for the measurement of digital skills, as the path evaluation is made transparent in relation to the acquired skills.

The headings were given every five weeks.

\section{The Experimentation}

The sample of the research consists of 162 students attending the course of Laboratory of General Education and Educational Technologies of the degree course in Primary Education Sciences of the University of Salerno. The course was delivered in e-learning. Participants aged between 19 and 27 years, and have taken the course in the first semester. 15/16 (from October to January), for a total of 60 hours, 3 credits.

The first month of the trial (October) was dedicated to the administration of the Instant DCA instrument, planning the activities for the promotion of digital skills. Various activities have been developed according to the guidelines provided by Calonghi [17], both as regards the textbooks used, both for the development of achievement tests [18].

In preparing the activities of the course, the aim was to situate the learner before problematic situations in order to 
enable him to identify the problem, formulated hypotheses for the resolution and evaluate the most appropriate solution. To support the learner, in that location have been presented not quite defined questions and therefore, it would stimulate reflection and would stimulate the resolution. This technique has enabled the self-reflection and self-evaluation by the learner, enabling true understanding of media messages.

Specifically we have been designed 15 activities, five for each activity: technological, cognitive and ethical.

In the next step, it realized in the months of November/December, was introduced on an experimental factor with the administration of 15 prepared activities. They were provided for 30 meetings of 2 hours duration each, for a total of 60 hours. In the first meetings administered activities were related to the technological dimension with the assignment of exercises aiming the promotion of skills and preparation of each learner exploring instructional design software. At each student was asked to highlight the capabilities and potential of the software and then, using synchronous and asynchronous tools (forum, blog, wiki, chat, email, etc.) test, through collaborative activities, design and detection of points of strengths and weaknesses of the software itself.

Every five meetings were characterized by the administration of the assessment rubrics to measure the activities of the learners.

After all matches the address books have been used by students as a self-assessment tool.
The last month (January), was dedicated to the processing of data obtained after administration of the five activities by the looks of the evaluation rubrics. Subsequently, it was served up the Instant DCA, which has allowed to establish the profiles of each learner.

Analysis of the results showed significant changes in students. In fact, if the initial analysis of the data was recorded in the Instant DCA tests, results showed quite low, these data undergo a marked improvement in the final test.

The graph below (Figure 1) shows the percentages of the average scores for each indicator:

As can be seen from the graph, the examines the technological dimension highlights, in students, a sufficient expertise, especially with regard to the identification of the interfaces and symbols (59\%) and for the resolution of technical problems $(52 \%)$. The technological understanding, however, showed a very low value (26\%).

The assessment of cognitive dimension detects poor skills concerning the organization of the data and tables and comparison with formal logic problems. Therefore, students do not show aptitude in knowledge of manipulation, interpretation and formulation of inferences. Manifest remarkable capacity only as regards the functioning with the text, that is, to read, select and interpret a text $(50 \%)$ and evaluate the information, according to their relevance and reliability, coming from the use of different media $(52 \%)$. 

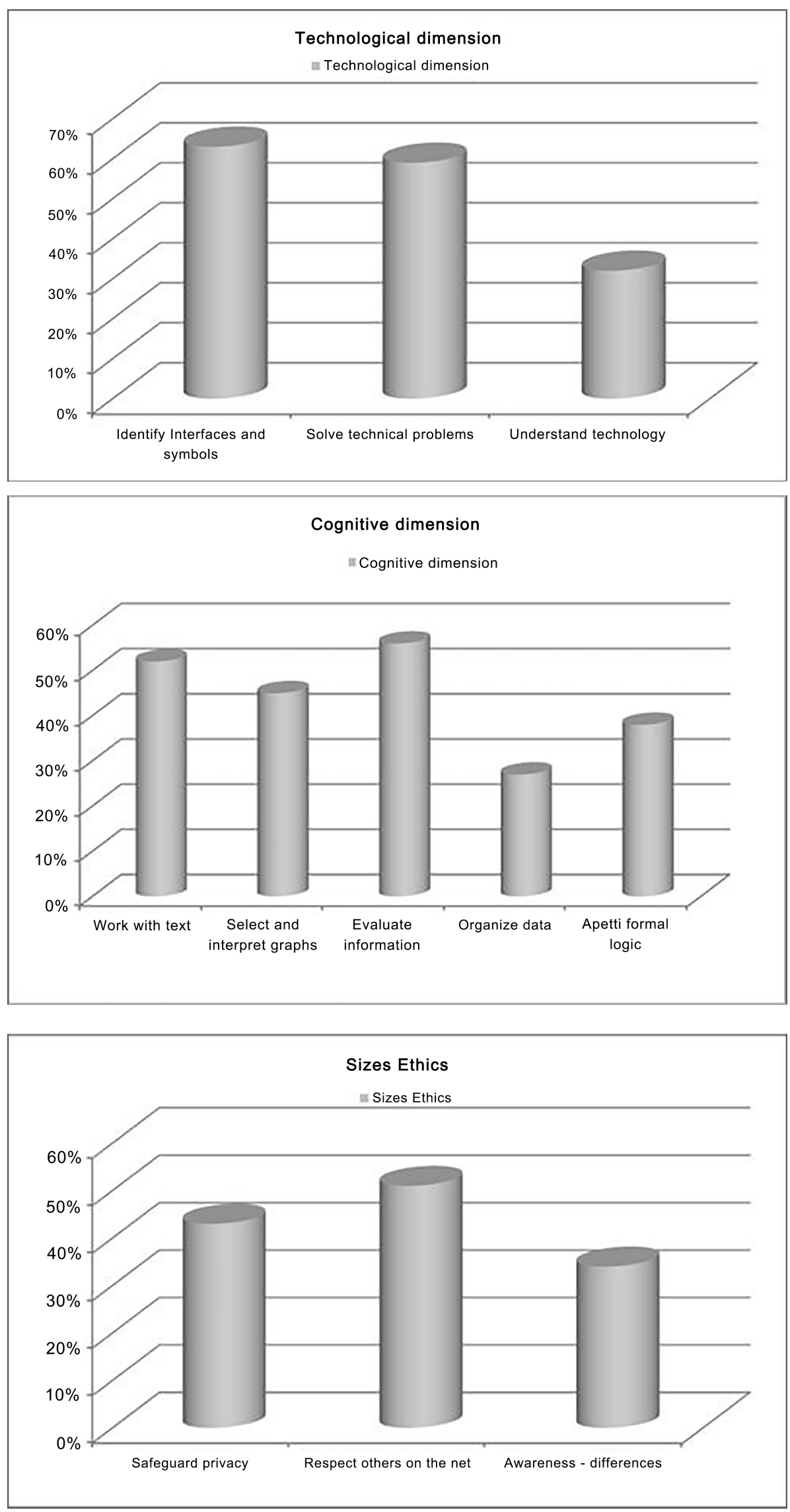

Figure 1. Percentage of average scores for each indicator 
Finally, data on the ethical dimension is present in a non-compliant. In fact, if on one hand the learners demonstrate complete knowledge regarding the respect of the users involved in the network (47\%), show little awareness in the protection of privacy $(40 \%)$ and knowledge of the differences (30\%).

The examines information obtained through the collection in the pipeline, carried out through the administration of the three headings of appraisal and articulated using the four elements constituting the model R-I-Z-A, on a qualitative level, are satisfactory. In fact, taking into consideration the evaluation of resources, implementing a comparison on the digital skills of learners at the beginning of the trial and the end, you can highlight a significant improvement $(86 \%)$, especially as regards the identification of the key concepts, their definition and the linking.

For the evaluation of the interpretation facilities was examined the difference of perceptions that students have expressed at the beginning and end of the experiment. It was found that $81 \%$ of participants achieved excellent performance levels in analyzing a media text, to provide value judgments on the medial relationship, recognizing the private emotions and in narrating the experience.

The differences between the learner's ability to design a media product or apply a storytelling model to a product, have allowed the evaluation of the action structures. The $76 \%$ of the learners, at the end of the experiment is capable of producing a medial message using the media linguistic rules and evaluate a message. In addition, they demonstrate a good understanding and identification of the features of the significant principles of a medial post. Specifically, the $72 \%$ is able to discriminate facts and actions by personal opinions, while $80 \%$ is able to select the relevant information, discarding or aside those superfluous.

Finally, the evaluation of self-regulation structures took over the student's ability to set goals and evaluate their actions with regard to their own learning.

Self-evaluation, implemented by the administration of sections to each individual learner, has allowed the pupil himself to reflect on the action undertaken up to that point and then, admitting a little awareness and consideration in implementing utilization strategies average.

The path therefore was evaluated in a very formative allowing to start the learning process autonomously and responsibly, tackling with commitment and perseverance the acquisition of future knowledge. Students achieved the ability to monitor the process useful for the solution of a problem, to check out the strategies adopted and correct them, if they are not relevant, resulting in increased performance.

The significance of the differences between the averages of the data detected by the Instant DCA, administered at the beginning and end of the experiment, was detected through the use of the application of T tests.

It was developed the confidence interval for the difference of $95 \%$ to accept as significant values of t. The statistical analysis found that the average value of the group, for each investigated dimensions: technological, cognitive, ethical, increased significantly at the end of the experiment, as shown in the graph (Figure 2)

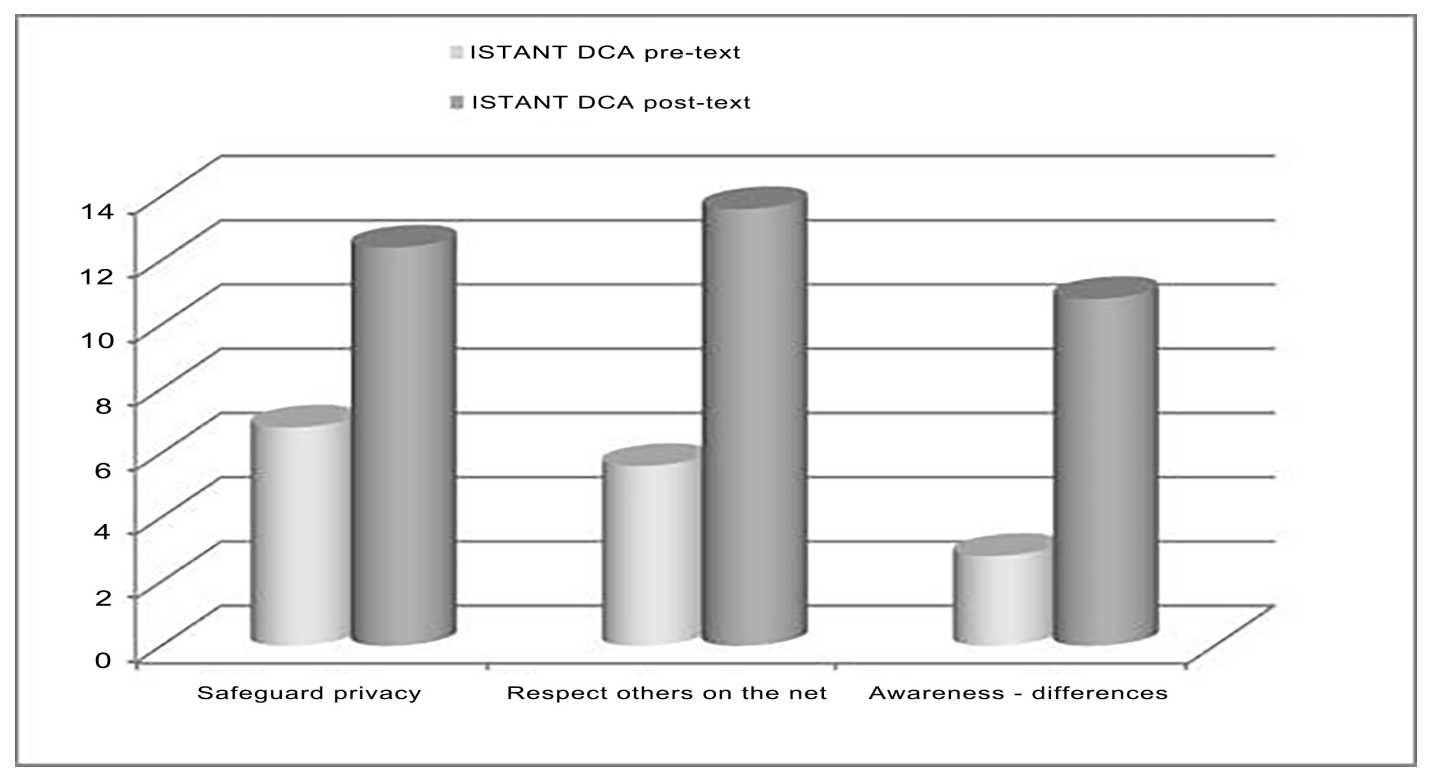

Figure 2. Average scores instant DCA pre-test and post-test 
The operating assumptions, prepared at the beginning of the trial, concerning the improvement of digital skills, have been largely achieved.

Specifically: the technological dimension, whose initial hypothesis was to test the selective ability, or the ability to select the relevant information for solving a specific problem; the ability to "surf" and orientate in hypertext structures, has been largely achieved as learners show vast capabilities in identifying critical technical situations and, above all, ability to find appropriate solutions; describe a flow of data and make the distinction between real and virtual.

The cognitive dimension, whose initial hypothesis was the acquisition of the ability to read and understand texts capacity, at the end of the experiment the students show a strong ability in finding substantial elements of information, selecting relevant information from the less important or useful, assuming a critical attitude towards them and you reprocess the contents in graphical and hypertext, also through the use of conceptual and mental maps.

Finally, the ethical dimension, relative to the assumption of responsibility on the media activities, has been reached, both as regards the management of personal data, and for increased awareness of the potential risks arising from the "Navigation" on the network. In addition, they highlight significant progress with regard to the respect of others, the identification of promoted values and understand their views and intentions.

\section{Conclusions}

The research was aimed to evaluate the behavior of young people regarding the use of the media and the role of the institutions responsible in this regard.

With the aid of e-learning platform it has been possible to design and implement different university educational interventions and more complex, but also more effective and motivating.

Experimentation has supported student teachers in the understanding and interpretation of media texts and to create new media products, but above all, made it possible to outline, effectively and efficiently, guidelines pertaining to the reading and writing process for understanding personal experiences.

As regards the institutions it is necessary that they are increasingly sensitized in the realization of interventions aimed at the implementation of educational activities valid and performing.

\section{REFERENCES}

[1] H. Gardner, Forma mentis: saggio sulla pluralità dell'intelligenza, Feltrinelli, Milano,1987.Unione Europea, Trattati consolidati. Carta dei diritti fondamentali, Marzo 2010.

[2] Unione Europea, Trattati consolidati. Carta dei diritti fondamentali, Marzo 2010.

[3] A. Calvani, A. Fini, M. Ranieri, Valutare la competenza digitale. Modelli teorici e strumenti applicativi, TD-Tecnologie Didattiche, 48(3), 39-46, 2009.

[4] P. Gilster, Digital Literacy, Wiley and Computer Publishing, New York, 1997, pp. 1-2.

[5] O. Erstad, La digital literacy nella scuola: l'esperienza norvegese Approfondimenti sul concetto di digital literacy e sulla sua relazione con il contesto socio-culturale norvegese ed europeo, TD-Tecnologie didattiche, 43(1), 4-11, 2008

[6] L. Qvortrup, Det lærende samfund. Hyperkompleksitet og viden. (The Learning Society. Hypercomplexity and knowledge), Gyldendal, Copenhagen, 2001.

[7] Commissione Europea, Raccomandazione del Parlamento Europeo e del Consiglio del 18 dicembre 2006 relativa alle competenze chiave per l'apprendimento permanente.

[8] D. Buckingham, Media Education. Literacy, Learning and Contemporary Culture, UK: Polity Cambridge, 2003.

[9] T. Grange Sergi, M. G. Onorati, La sfida della comunicazione all'educazione. Prospettive di media education, Franco Angeli, Milano, 2007, p. 68.

[10] P. C. Rivoltella, Neurodidattica. Insegnare al cervello che apprende, Raffaello Cortina, Milano, 2012, p. 139.

[11] A. Calvani, A. Fini, M. Ranieri, La competenza digitale nella scuola, Erickson, Trento, 2011; A. Calvani, A. Fini, M. Ranieri, Valutare la competenza digitale. Prove per la scuola primaria e secondaria, Erickson, Trento, 2010.

[12] R. Trinchero, Valutare l'apprendimento nell'e-learning. Dalle abilità alle competenze, Erickson, Trento, 2006, pp. 195-229.

[13] R. Trinchero, Valutare l'apprendimento nell'e-learning. Dalle abilità alle competenze, Erickson, Trento, 2006, pp. 195-229.

[14] R. Trinchero, Costruire, valutare, certificare competenze. Proposte di attività per la scuola, Franco Angeli, Milano, 2012.

[15] F. Pedone, Valorizzazione degli stili e promozione dell'apprendimento autoregolato. Teorie e strumenti per una didattica meta cognitiva, Junior, Bergamo, 2012.

[16] M. Castoldi, M. Martini, Verso le competenze: una bussola per la scuola. Progetti didattici e strumenti valutativi, Franco Angeli, Milano, 2011.

[17] L. Calonghi, Redazione e sperimentazione di libri di testo per la scuola dell'obbligo, Orientamenti pedagogici n. 2, 1979, pp. 293-315.

[18] L. Calonghi, I test di acquisizione e di profitto, in C. Scarpellini, E. Strologo (Eds.) Orientamento, La Scuola, Brescia, 1976, pp. 767-841. 